\title{
A phase II study of ipilimumab plus temozolomide in patients with metastatic melanoma
}

\author{
Sapna P. Patel ${ }^{\mathrm{a}}$, Dae Won Kim ${ }^{\mathrm{a}, 1}$, Roland L. Bassett ${ }^{\mathrm{b}}$, Suzanne Cain ${ }^{\mathrm{a}}$, Edwina Washington ${ }^{\mathrm{a}}$, \\ Wen-Jen Hwu ${ }^{a}$, Kevin B. Kim ${ }^{a}, 2$, Nicholas E. Papadopoulos ${ }^{a}$, Jade Homsi ${ }^{a, 3}$, Patrick Hwu ${ }^{a}$, \\ and Agop Y. Bedikian ${ }^{a}$ \\ aThe University of Texas MD Anderson Cancer Center, Department of Melanoma Medical \\ Oncology, 1515 Holcombe Blvd, Houston, Texas, USA 77030 \\ 'The University of Texas MD Anderson Cancer Center, Department of Biostatistics, Houston, \\ Texas, 1515 Holcombe Blvd, Houston, Texas USA 77030
}

\begin{abstract}
Checkpoint blockade has revolutionized the treatment of melanoma; however, it benefits only the minority of patients. Several agents have been combined with immunotherapy to improve T-cell activation and persistence including growth factor, chemotherapy, and radiation. Preclinical data suggest temozolomide, which metabolizes to the same active compound as dacarbazine, selectively depletes regulatory $\mathrm{T}$ cells. This potential immunomodulatory effect of temozolomide provides rationale for combination with ipilimumab.
\end{abstract}

\begin{abstract}
We performed an open-label single-arm phase II study of ipilimumab plus temozolomide in the frontline setting for patients with metastatic melanoma and $\mathrm{LDH}<=2 \mathrm{x}$ upper limit of normal. Ipilimumab was given at $10 \mathrm{mg} / \mathrm{kg}$ on day 1 and temozolomide $200 \mathrm{mg} / \mathrm{m}^{2}$ orally days $1-4$ every three weeks for four doses followed by maintenance ipilimumab every 12 weeks plus temozolomide every four weeks. The primary objective of the study was 6-month PFS.
\end{abstract}

A total of 64 patients were enrolled and the 6-month PFS was $45 \%$ with median OS of 24.5 months. There were $10(15.6 \%)$ confirmed partial responses and $10(15.6 \%)$ confirmed complete responses. Duration of response amongst responders is 35 months with 10 patients demonstrating an ongoing response at median follow-up of 20 months. There were no deaths or unexpected

\footnotetext{
Corresponding Author: Direct all correspondence to Sapna Patel, M.D., 1515 Holcombe Blvd, Houston, TX, USA 77030, Tel: (713) 792-2921, Fax: (713) 745-1046, < sppatel@mdanderson.org>.

Sapna Patel and Dae Won Kim contributed equally to this work.

1Present Address: Moffitt Cancer Center, 12902 USF Magnolia Dr., Tampa, Florida, USA 33612

2Present Address: California Pacific Medical Center, 2323 Sacramento St. \#2, San Francisco, California, USA 94115

${ }^{3}$ Present Address: The University of Texas Banner MD Anderson Cancer Center, 2946 E Banner Gateway Dr., Gilbert, Arizona, USA 85234

Note on previous publications: This work was presented in its preliminary form at the American Society of Clinical Oncology (ASCO) 2012 Annual Meeting, Chicago, IL, USA June 1, 2012 and the European Society of Medical Oncology (ESMO) 2012 Annual Meeting, Vienna, Austria, October 1, 2012.

Authors contributions

This manuscript was prepared by the two first co-authors, but all the authors contributed to patient enrollment, collection, and subsequent drafts of the manuscript.

Conflict of Interest

All other authors declare that they have no conflict of interest.
} 
toxicities on study. The most common gastrointestinal side effects were nausea and constipation rather than diarrhea or colitis.

These results suggest that the combination of induction ipilimumab plus temozolomide could potentially be an effective strategy to enhance antitumor activity with a manageable toxicity profile. These findings warrant further evaluation in a large prospective study.

\section{Keywords}

ipilimumab; temozolomide; melanoma; clinical trial; regulatory T cells

\section{Introduction}

Metastatic melanoma is one of the most aggressive solid tumors, and the treatment of metastatic melanoma is quite challenging. The recent advancement of tumor immunology has led to the development of checkpoint inhibitors such as ipilimumab, pembrolizumab and nivolumab which have changed the landscape of advanced melanoma treatment. Among them, ipilimumab is the first immune checkpoint blockade approved by US Food and Drug Administration (FDA) for patients with advanced melanoma, and it has become one of the most common standard treatment options for advanced melanoma. Ipilimumab is a recombinant human monoclonal antibody against cytotoxic T-lymphocyte antigen (CTLA-4). It affects the immune system by inhibiting the suppression of T-cell function. As a result, activated T-cells remain stimulated and are able to exert antitumor effects. Recently, long term follow-up clinical data of ipilimumab have shown the durable survival benefit.[1] However, the durable clinical benefit is limited to selected patients with low response rates of $10 \% .[2,3]$ To improve its low clinical response rate, the combination of ipilimumab with other agents including cytotoxic chemotherapy, cancer vaccine, high dose interleukin-2, immune co-stimulatory molecules and other checkpoint inhibitors has been examined. Especially, there is a growing interest in combination of immunotherapy with chemotherapy. Previously, cytotoxic chemotherapeutic agents were considered to be highly immunosuppressive since they induce bone marrow suppression and lymphopenia. However, there is a growing body of evidence that certain chemotherapeutic agents may enhance antitumor immunity by inhibition of tumor induced immune suppression, induction of immunologic tumor cell death, activation of innate immune systems, direct stimulation of $\mathrm{T}$ cells or depletion of immune suppressive cells such as regulatory $\mathrm{T}$ cells (Treg) and myeloid derived suppressor cells (MDSC).[4]

Temozolomide is a congener of dacarbazine, which is the only chemotherapeutic agent approved by the FDA for metastatic melanoma with $100 \%$ oral bioavailability and similar clinical activity for patients with metastatic melanoma.[5] In contrast to dacarbazine, temozolomide crosses the blood-brain barrier, and it has been reported that temozolomide induces depletion of regulatory $\mathrm{T}$ cells (Treg) and suppression of Treg function in preclinical and clinical studies.[6,7] Therefore, temozolomide may enhance antitumor immunity of ipilimumab by reduction of tumor burden and depletion and suppression of Treg. Here, we investigated the safety and efficacy of ipilimumab at $10 \mathrm{mg} / \mathrm{kg}$ in combination with an oral alkylating agent, temozolomide. 


\section{Methods}

This was a single-institution open-label, single-arm phase II clinical trial designed to evaluate the safety, tolerability, and efficacy of ipilimumab at a dose of $10 \mathrm{mg} / \mathrm{kg}$ when combined with temozolomide. The primary objective of the study was progression-free survival (PFS) at 6 months. The protocol was approved by the institutional review board at the University of Texas MD Anderson Cancer Center and conducted under the principles of the International Council for Harmonisation and Good Clinical Practice. The study was designed in conjunction with representatives of the sponsor, Bristol-Myers Squibb (New York, NY). All patients provided written informed consent prior to enrollment. The sponsor had no role in data collection, data analysis, data interpretation, or writing of the report.

\section{Patient selection}

We enrolled patients between the ages of 18 and 75 with previously untreated unresectable Stage III or Stage IV cutaneous melanoma. Patients may have received prior adjuvant therapy but no prior therapy for advanced disease, and were required to have an Eastern Cooperative Oncology Group (ECOG) performance status of 0 or 1 . Brain metastases were allowed, so long as they were asymptomatic and not using corticosteroids or so long as the symptomatic lesions were treated and stable for at least 4 weeks. Measurable disease and was defined using immune-related response criteria (irRC) with target lesions measurable in two dimensions at least $10 \mathrm{~mm} \times 10 \mathrm{~mm}$. Baseline characteristics are listed in Table 1 .

\section{Treatment plan}

Induction phase consisted of ipilimumab (Bristol-Myers Squibb; New York, NY) administered intravenously over 90 minutes at a dose of $10 \mathrm{mg} / \mathrm{kg}$ on Day 1 and oral temozolomide (Merck \& Co., Inc.; Whitehouse Station, NJ) $200 \mathrm{mg} / \mathrm{m}^{2}$ on Days 1-4 every three weeks for four doses. Maintenance phase began at week 12 and consisted of ipilimumab $10 \mathrm{mg} / \mathrm{kg}$ on Day 1 repeated every twelve weeks and temozolomide $200 \mathrm{mg} / \mathrm{m}^{2}$ on Days 1-5 starting week 12 and repeated every 4 weeks until disease progression or unacceptable toxicity occurred. Temozolomide in the maintenance setting was left to the discretion of the investigator.

\section{Response evaluation}

Radiological assessment was performed with computed tomography and or magnetic resonance imaging after the second and fourth induction cycles, around weeks 6 and 12. It was then performed every 12 weeks. Objective responses were evaluated using immunemediated response criteria where a partial response is defined as a decrease in cumulative tumor burden by at least $50 \%$ confirmed at least 4 weeks later and complete response is defined as a total disappearance at target and non-target lesions confirmed at least 4 weeks later.

Adverse events were graded according to the National Cancer Institute Common Terminology Criteria for Adverse Events, version 3.0 (http://ctep.info.nih.gov/ protocolDevelopment/electronic_applications/docs/ctcae3.pdf). Adverse events were reported from the date of the first dose until resolution of adverse event or until death. 


\section{Statistical analysis}

The primary objective of this study was PFS at 6 months. PFS was estimated using the method of Kaplan-Meier and was calculated from the start of study until disease progression or death, whichever came first. Patients who were not evaluable at 6 months were considered failures (i.e. disease progression occurred). The target PFS rate at 6 months in this study was at least $30 \%$ with a null hypothesis of $15 \%$ seen with standard of care dacarbazine or temozolomide. A Simon's minimax two-stage design was used to perform interim efficacy monitoring. With 64 patients, this study had $90 \%$ power and the type I error of 0.05 . Under these assumptions, the probability of rejecting an effective combination treatment was $10 \%$. Data analysis was performed using SPSS Statistics 22 (IBM, Armonk, New York, USA).

\section{Results \\ Patient characteristics}

Between June 2010 and August 2011, a total of 64 patients were enrolled and treated with ipilimumab plus temozolomide. The baseline characteristics of the patients are listed in Table 1. Median age was 62 years (range 33-75) and 45 patients (70\%) were male. Among enrolled patients, 53 (83\%) had ECOG performance status of 0, 31 (48\%) had stage IV M1c disease and 13 (20\%) had elevated LDH. Two patients (3\%) had brain metastatic disease before starting the treatment.

\section{Treatment}

The median number of doses was 5 (range 2-20). Forty-five patients (70\%) received all 4 induction doses of ipilimumab plus temozolomide, of which $32(50 \%)$ received the fifth consolidation dose at week 12 . Thirty-eight patients (59\%) discontinued the treatment due to disease progression and 18 (28\%) patients discontinued treatment because of an adverse event, of which 15 (23\%) were drug-related. Two patients withdrew consent and one patient died before their first tumor response evaluation.

\section{Efficacy}

Response analyses were performed on the intention-to-treat population. To date, there have been $10(15 \cdot 6 \%)$ confirmed partial responses and $10(15 \cdot 6 \%)$ confirmed complete responses (Figure 1). At data cutoff, among patients experiencing an objective response, the median duration of response was 35 months (range: 2-57) (Figure 2). There are 10 patients with an ongoing response, including 8 complete responders. At a median follow-up of 20 months (range: 2-60), PFS at 6 months was 45\%, median PFS was 5 months and median overall survival (OS) was 24.5 months (Figure 3). PFS, response, and OS was assessed using Fisher's exact test in the subgroups of patients with and without bone and liver metastases. PFS was significantly decreased in the group with bone metastasis compared to the group without bone metastasis (Figure 4) but not in the group with liver metastasis. Additionally, no objective responses were observed in patients' bone metastasis sites while three of 14 patients $(21 \%)$ with liver metastasis had a confirmed complete response and one patient (7\%) had a confirmed partial response in the liver. One patient with both liver and bone metastasis generated a confirmed partial response but this was driven by response in her liver 
while her bone metastasis progressed on treatment. Progression of disease was defined using irRC as progression in total tumor burden (target and non-target lesions) by at least $25 \%$ compared with nadir time point. This assessment is limited by the fact that bone lesions are not measurable per irRC. Tumor assessments of bone lesions on computed tomography (CT) scans were measured in two dimensions, however, there was no accounting for increased calcification or other signs of tumor response other than size.

\section{Toxicity and immune-related adverse events}

The most common drug-related toxicity was pruritus (87.5\%) followed by skin rash (83\%). The most common gastrointestinal toxicity was nausea $(76.5 \%)$, followed by constipation (70\%), and diarrhea (56\%). Immune related adverse events included colitis in $11 \%$ of patients, and elevations in alanine aminotransferase (ALT) and aspartate aminotransferase (AST), $45 \%$ and $42 \%$, respectively. Hematologic toxicities were as follows: anemia (66\%), thrombocytopenia (37.5\%), and lymphopenia (23\%). Grade 3 or 4 toxicities were infrequent and occurred mainly in 1-2 patients (Table 2). The Grade 3 or 4 toxicities that occurred in more than two patients were Grade 3 skin rash (9\%), Grade 3 diarrhea (8\%), Grade 3 pruritus (6\%), and Grade 3 thrombocytopenia (5\%). There were no drug-related Grade 5 events.

\section{Discussion}

This phase II study establishes clinical activity in ipilimumab plus temozolomide in the frontline setting. This combination demonstrates higher efficacy than previously reported ipilimumab $10 \mathrm{mg} / \mathrm{kg}$ studies[8,9] but a similar efficacy to the phase II NIBIT-M1 study of ipilimumab plus fotemustine.[10]

Immune-related and non-immune-related Grade 3 or 4 adverse events were low in our study compared with NIBIT-M1, and this may be in part due to the side effect profile of temozolomide. The most common gastrointestinal side effects noted in our study were nausea followed by constipation. These represent the two most common side effects to oral temozolomide use. Diarrhea did occur in 56\% of patients, with documented colitis in $11 \%$ (radiographic or pathologic diagnosis). This higher frequency of diarrhea is associated with the higher dose of ipilimumab.

The combination strategy of ipilimumab with other therapeutic agents have been extensively studied to enhance antitumor activity. Specifically, ipilimumab plus dacarbazine, which is a congener of temozolomide, has been evaluated in several clinical trials.[9,11] Although it is not feasible to make direct comparisons of clinical outcome with the studies due to different study designs and doses, our objective response rate of 31\% (15.6\% partial response; $15.6 \%$ complete response) and median OS of 24.5 months are almost twice of the objective response rate of $14-15 \%$ and the median OS of 11-14 months with ipilimumab plus dacarbazine studies. The remarkable clinical outcome in our study could be attributed to several factors: 1) the higher dose of ipilimumab 2) the concomitant use of temozolomide 3) the treatment-naïve population 4) the use of irRC as opposed to conventional RECIST. Although early dose-finding studies noted an increase in clinical activity of ipilimumab with increasing doses [8], the aforementioned phase III study of ipilimumab at $10 \mathrm{mg} / \mathrm{kg}$ with 
dacarbazine showed a $15 \%$ response rate, which is not a notable increase over ipilimumab 3 $\mathrm{mg} / \mathrm{kg}$ response rate of $11 \%$ or ipilimumab at $3 \mathrm{mg} / \mathrm{kg}$ plus dacarbazine of $14 \% .[9,3,11]$ Thus, it is not clear that increasing ipilimumab dose from $3 \mathrm{mg} / \mathrm{kg}$ to $10 \mathrm{mg} / \mathrm{kg}$ is solely responsible for the higher response rate in this study. Furthermore, recent data from a 3 $\mathrm{mg} / \mathrm{kg}$ versus $10 \mathrm{mg} / \mathrm{kg}$ phase III study of ipilimumab demonstrated no difference in objective response rates, though the higher dose of ipilimumab was associated with improved survival.[12] The addition of temozolomide represents a different maneuver than the addition of dacarbazine to ipilimumab. Temozolomide demonstrates a preferentially cytotoxic effect to regulatory $\mathrm{T}$ cells (Treg) rather than effector T cells (Teff).[6,7] This may explain the higher clinical responses in combination with ipilimumab, as a greater proportion of activated Teff were left in the tumor microenvironment compared to Treg. Previous studies have highlighted the importance of this ratio of effector to regulatory immune cells in generating a response to immunotherapy.[13,14] One limitation of our study is the lack of correlative studies to support abrogation of the Teff:Treg ratio as a mechanism of response. Because constipation was more prevalent than diarrhea, patients in our study were able to stay on treatment longer, with $70 \%$ receiving all 4 induction doses of ipilimumab at $10 \mathrm{mg} / \mathrm{kg}$ in comparison to $44 \%$ in the ipilimumab plus dacarbazine studies (44\%) which can also explain better clinical outcome in our study. The use of this combination in the frontline setting only minimally contributed to the notable response rate of $31 \%$. The proportion of patients with Stage IV M1c disease (two with treated brain metastasis) was $48 \%$, and $20 \%$ of patients had an elevated LDH, representing an advanced metastatic melanoma disease state. The randomized phase II and III studies of ipilimumab at $3 \mathrm{mg} / \mathrm{kg}$ or $10 \mathrm{mg} / \mathrm{kg}$ plus dacarbazine were also used in the frontline setting, and response rates to the combination were lower, as mentioned, indicating that the previously untreated metastatic melanoma population is an unlikely reason for higher response rates in our study. The different response criteria may also be one of the contributing factors to the different clinical outcomes. In this study, we used irRC while the ipilimumab plus dacarbazine studies used conventional RECIST, criteria which can underestimate the clinical benefit in patients with atypical responses to immune checkpoint inhibitor therapy.[15,16] However, objective response rates are not significantly different between the two criteria in a large retrospective study.[17] Therefore, response criteria is not completely responsible for the remarkable clinical outcome in our study.

One of the deficits of our study was the lack of correlative lymphocyte blood samples to support some of the hypothesis defining the higher response rate with the addition of temozolomide. Responders who are not lost to follow-up have the potential to have their peripheral blood analyzed for a lymphocyte marker of response. Without the entire study population, however, the true predictive nature of any blood marker will be unclear. This highlights the need for immunotherapy studies to have ongoing immune monitoring built in early-on or from the outset, should clinical benefit be analyzed alongside blood or tumor samples.

One corollary observation from this study is that the benefit of immune responses is rare or absent in metastatic bone lesions. While lung, liver, nodal, and other soft tissue metastatic sites showed response to treatment with ipilimumab plus temozolomide, no patients' bone metastatic sites responded to treatment. One confirmed partial responder with liver and bone 
metastasis was noted to have response in the liver with progression of soft-tissue-associated bone metastasis. The regulation of osteoblasts is influenced by a variety of pro-resorption and anti-resorption cytokines. These cytokines, such as interleukin (IL)-1, tumor necrosis factor alpha (TNF-a), IL-6, IL-11, IL-17, and interferon-gamma (IFN- $\gamma$ ) affect the proinflammatory and anti-inflammatory trafficking of cytotoxic and regulatory lymphocytes. [18] Additionally, receptor activator of nuclear factor- $\kappa \mathrm{B}$ ligand (RANKL) is present in bone cells, as well as during deletion of self-reactive T cells during thymic development. RANKL may also modify dendritic cells to maintain Treg population, in an effort to avoid selfreaction or auto-immunity in bone.[19] While these mechanisms may explain some of the reasons why responses in bone metastasis are not common with ipilimumab, the osteoimmunology of pathologic bone metastasis is not clearly understood in relation to checkpoint blockade, but is an interesting area of future study.

Since 2011, an improvement in OS has been demonstrated in metastatic melanoma patients treated with ipilimumab. This benefit appears to be uncoupled from overall response rate, with more than one-fifth of patients alive at 5 years of follow-up after treatment with ipilimumab.[1] Several agents have been added to ipilimumab, in an attempt to either improve overall response rates or improve OS. Fotemustine in addition to ipilimumab at 10 $\mathrm{mg} / \mathrm{kg}$ improved response rate while sargramostim in addition to ipilimumab $10 \mathrm{mg} / \mathrm{kg}$ noted an improvement in median OS.[10,20] Temozolomide in combination with ipilimumab $10 \mathrm{mg} / \mathrm{kg}$ demonstrates an impressive response rate (31\%) and median OS (24.5 months). Given the plausibility that the clinical benefit may be driven in part by reduction of serious ipilimumab side effects and Treg function by temozolomide, it is not yet clear if temozolomide plus ipilimumab at $3 \mathrm{mg} / \mathrm{kg}$ will offer similar results. Additionally, as the median number of cycles received in this study was 5, the utility of maintenance ipilimumab or temozolomide is unknown. However, an induction regimen of ipilimumab plus temozolomide (4 cycles) for the treatment of metastatic melanoma remains of interest due to its effect on clinical outcome, its finite treatment duration, and the commercial availability of both agents.

\section{Acknowledgments}

Funding

The clinical trial was sponsored by Bristol-Myers Squibb and the work supported by the MD Anderson Cancer Center Support Grant P30CA016672

Dr. Patel reports clinical trial support from Bristol-Myers Squibb for conduct of the study; non-promotional speakers fees from Bristol-Myers Squibb Mexico, non-promotional speakers fees from Merck \& Co, advisory board honoraria from Amgen and Genentech, and clinical trial support from Novartis, Glaxo SmithKline, Reata, and Deciphera outside the submitted work. Dr. WJ Hwu reports clinical trial support from Bristol-Myers Squibb, Merck, Glaxo SmithKline, and Medimmune outside the submitted work. Dr. KB Kim reports clinical trial funding and speakers fees from Bristol-Myers Squibb outside the submitted work. Dr. P Hwu is an advisory board member for Lion Biotechnologies and Immatics.

\section{ABBREVIATIONS}

AST aspartate aminotransferase

ALT alanine aminotransferase 


$\begin{array}{ll}\text { CT } & \text { computed tomography } \\ \text { ECOG } & \text { Eastern Cooperative Oncology Group } \\ \text { FDA } & \text { Food and Drug Administration } \\ \text { IFN- } \gamma & \text { interferon-gamma } \\ \text { irRC } & \text { immune-related response criteria } \\ \text { PFS } & \text { progression-free survival } \\ \text { RANKL } & \text { receptor activator of nuclear factor- } \mathrm{kB} \text { ligand } \\ \text { Teff } & \text { effector T cells } \\ \text { TNF-a } & \text { tumor necrosis factor alpha } \\ \text { Treg } & \text { regulatory T cells }\end{array}$

\section{References}

1. Schadendorf D, Hodi FS, Robert C, Weber JS, Margolin K, Hamid O, Patt D, Chen TT, Berman DM, Wolchok JD. Pooled Analysis of Long-Term Survival Data From Phase II and Phase III Trials of Ipilimumab in Unresectable or Metastatic Melanoma. J Clin Oncol. 2015; 33(17):1889-1894. DOI: 10.1200/JCO.2014.56.2736 [PubMed: 25667295]

2. Robert C, Schachter J, Long GV, Arance A, Grob JJ, Mortier L, Daud A, Carlino MS, McNeil C, Lotem M, Larkin J, Lorigan P, Neyns B, Blank CU, Hamid O, Mateus C, Shapira-Frommer R, Kosh M, Zhou H, Ibrahim N, Ebbinghaus S, Ribas A, investigators K. Pembrolizumab versus Ipilimumab in Advanced Melanoma. N Engl J Med. 2015; 372(26):2521-2532. DOI: 10.1056/NEJMoa1503093 [PubMed: 25891173]

3. Hodi FS, O'Day SJ, McDermott DF, Weber RW, Sosman JA, Haanen JB, Gonzalez R, Robert C, Schadendorf D, Hassel JC, Akerley W, van den Eertwegh AJ, Lutzky J, Lorigan P, Vaubel JM, Linette GP, Hogg D, Ottensmeier CH, Lebbe C, Peschel C, Quirt I, Clark JI, Wolchok JD, Weber JS, Tian J, Yellin MJ, Nichol GM, Hoos A, Urba WJ. Improved survival with ipilimumab in patients with metastatic melanoma. N Engl J Med. 2010; 363(8):711-723. DOI: 10.1056/NEJMoa1003466 [PubMed: 20525992]

4. Bracci L, Schiavoni G, Sistigu A, Belardelli F. Immune-based mechanisms of cytotoxic chemotherapy: implications for the design of novel and rationale-based combined treatments against cancer. Cell Death Differ. 2014; 21(1):15-25. DOI: 10.1038/cdd.2013.67 [PubMed: 23787994]

5. Middleton MR, Lee SM, Arance A, Wood M, Thatcher N, Margison GP. O6-methylguanine formation, repair protein depletion and clinical outcome with a $4 \mathrm{hr}$ schedule of temozolomide in the treatment of advanced melanoma: results of a phase II study. Int J Cancer. 2000; 88(3):469-473. [PubMed: 11054678]

6. Banissi C, Ghiringhelli F, Chen L, Carpentier AF. Treg depletion with a low-dose metronomic temozolomide regimen in a rat glioma model. Cancer Immunol Immunother. 2009; 58(10):16271634. DOI: 10.1007/s00262-009-0671-1 [PubMed: 19221744]

7. Ridolfi L, Petrini M, Granato AM, Gentilcore G, Simeone E, Ascierto PA, Pancisi E, Ancarani V, Fiammenghi L, Guidoboni M, de Rosa F, Valmorri L, Scarpi E, Nicoletti SV, Baravelli S, Riccobon A, Ridolfi R. Low-dose temozolomide before dendritic-cell vaccination reduces (specifically) CD4+CD25++Foxp3+ regulatory T-cells in advanced melanoma patients. J Transl Med. 2013; 11:135.doi: 10.1186/1479-5876-11-135 [PubMed: 23725550]

8. Wolchok JD, Neyns B, Linette G, Negrier S, Lutzky J, Thomas L, Waterfield W, Schadendorf D, Smylie M, Guthrie T Jr, Grob JJ, Chesney J, Chin K, Chen K, Hoos A, O’Day SJ, Lebbe C. Ipilimumab monotherapy in patients with pretreated advanced melanoma: a randomised, double- 
blind, multicentre, phase 2, dose-ranging study. Lancet Oncol. 2010; 11(2):155-164. DOI: 10.1016/ S1470-2045(09)70334-1 [PubMed: 20004617]

9. Robert C, Thomas L, Bondarenko I, O’Day S, Weber J, Garbe C, Lebbe C, Baurain JF, Testori A, Grob JJ, Davidson N, Richards J, Maio M, Hauschild A, Miller WH Jr, Gascon P, Lotem M, Harmankaya K, Ibrahim R, Francis S, Chen TT, Humphrey R, Hoos A, Wolchok JD. Ipilimumab plus dacarbazine for previously untreated metastatic melanoma. N Engl J Med. 2011; 364(26): 2517-2526. DOI: 10.1056/NEJMoa1104621 [PubMed: 21639810]

10. Di Giacomo AM, Ascierto PA, Pilla L, Santinami M, Ferrucci PF, Giannarelli D, Marasco A, Rivoltini L, Simeone E, Nicoletti SV, Fonsatti E, Annesi D, Queirolo P, Testori A, Ridolfi R, Parmiani G, Maio M. Ipilimumab and fotemustine in patients with advanced melanoma (NIBITM1): an open-label, single-arm phase 2 trial. Lancet Oncol. 2012; 13(9):879-886. DOI: 10.1016/ S1470-2045(12)70324-8 [PubMed: 22894884]

11. Hersh EM, O’Day SJ, Powderly J, Khan KD, Pavlick AC, Cranmer LD, Samlowski WE, Nichol GM, Yellin MJ, Weber JS. A phase II multicenter study of ipilimumab with or without dacarbazine in chemotherapy-naive patients with advanced melanoma. Invest New Drugs. 2011; 29(3):489498. DOI: 10.1007/s10637-009-9376-8 [PubMed: 20082117]

12. Ascierto PA, Del Vecchio M, Robert C, Mackiewicz A, Chiarion-Sileni V, Arance A, Lebbe C, Bastholt L, Hamid O, Rutkowski P, McNeil C, Garbe C, Loquai C, Dreno B, Thomas L, Grob JJ, Liszkay G, Nyakas M, Gutzmer R, Pikiel J, Grange F, Hoeller C, Ferraresi V, Smylie M, Schadendorf D, Mortier L, Svane IM, Hennicken D, Qureshi A, Maio M. Ipilimumab $10 \mathrm{mg} / \mathrm{kg}$ versus ipilimumab $3 \mathrm{mg} / \mathrm{kg}$ in patients with unresectable or metastatic melanoma: a randomised, double-blind, multicentre, phase 3 trial. Lancet Oncol. 2017; doi: 10.1016/ S1470-2045(17)30231-0

13. Radvanyi LG, Bernatchez C, Zhang M, Fox PS, Miller P, Chacon J, Wu R, Lizee G, Mahoney S, Alvarado G, Glass M, Johnson VE, McMannis JD, Shpall E, Prieto V, Papadopoulos N, Kim K, Homsi J, Bedikian A, Hwu WJ, Patel S, Ross MI, Lee JE, Gershenwald JE, Lucci A, Royal R, Cormier JN, Davies MA, Mansaray R, Fulbright OJ, Toth C, Ramachandran R, Wardell S, Gonzalez A, Hwu P. Specific lymphocyte subsets predict response to adoptive cell therapy using expanded autologous tumor-infiltrating lymphocytes in metastatic melanoma patients. Clin Cancer Res. 2012; 18(24):6758-6770. DOI: 10.1158/1078-0432.CCR-12-1177 [PubMed: 23032743]

14. Fateh S, Schell TD, Gingrich R, Neves RI, Drabick JJ. Unsuccessful high dose IL-2 therapy followed immediately by near continuous low dose temozolomide can result in rapid durable complete and near-complete remissions in metastatic melanoma. Cancer Biol Ther. 2010; 10(11): 1091-1097. [PubMed: 20930514]

15. Hodi FS, Hwu WJ, Kefford R, Weber JS, Daud A, Hamid O, Patnaik A, Ribas A, Robert C, Gangadhar TC, Joshua AM, Hersey P, Dronca R, Joseph R, Hille D, Xue D, Li XN, Kang SP, Ebbinghaus S, Perrone A, Wolchok JD. Evaluation of Immune-Related Response Criteria and RECIST v1.1 in Patients With Advanced Melanoma Treated With Pembrolizumab. J Clin Oncol. 2016; 34(13):1510-1517. DOI: 10.1200/JCO.2015.64.0391 [PubMed: 26951310]

16. Wolchok JD, Hoos A, O’Day S, Weber JS, Hamid O, Lebbe C, Maio M, Binder M, Bohnsack O, Nichol G, Humphrey R, Hodi FS. Guidelines for the evaluation of immune therapy activity in solid tumors: immune-related response criteria. Clin Cancer Res. 2009; 15(23):7412-7420. DOI: 10.1158/1078-0432.CCR-09-1624 [PubMed: 19934295]

17. Kurra, V., Sullivan, RJ., Gainor, JF., Hodi, FS., Gandhi, L., Sadow, CA., Harris, GJ., Flaherty, K., Lee, S. Pseudoprogression in cancer immunotherapy: Rates, time course and patient outcomes. $J$ Clin Oncol 34 (suppl; abstr 6580). 2016 ASCO Annual Meeting; Chicago, IL, USA. June 3, 2016; 2016. Poster

18. Walsh MC, Kim N, Kadono Y, Rho J, Lee SY, Lorenzo J, Choi Y. Osteoimmunology: interplay between the immune system and bone metabolism. Annu Rev Immunol. 2006; 24:33-63. DOI: 10.1146/annurev.immunol.24.021605.090646 [PubMed: 16551243]

19. Danks L, Takayanagi H. Immunology and bone. J Biochem. 2013; 154(1):29-39. DOI: 10.1093/jb/ mvt049 [PubMed: 23750028]

20. Hodi FS, Lee S, McDermott DF, Rao UN, Butterfield LH, Tarhini AA, Leming P, Puzanov I, Shin D, Kirkwood JM. Ipilimumab plus sargramostim vs ipilimumab alone for treatment of metastatic 
melanoma: a randomized clinical trial. JAMA. 2014; 312(17):1744-1753. DOI: 10.1001/jama. 2014.13943 [PubMed: 25369488] 


\section{Précis}

Ipilimumab plus temozolomide results in an improvement in response rate, overall survival, and gastrointestinal toxicity. The advantage of this regimen is the duration of benefit, finite treatment schedule and commercial availability of both agents. 


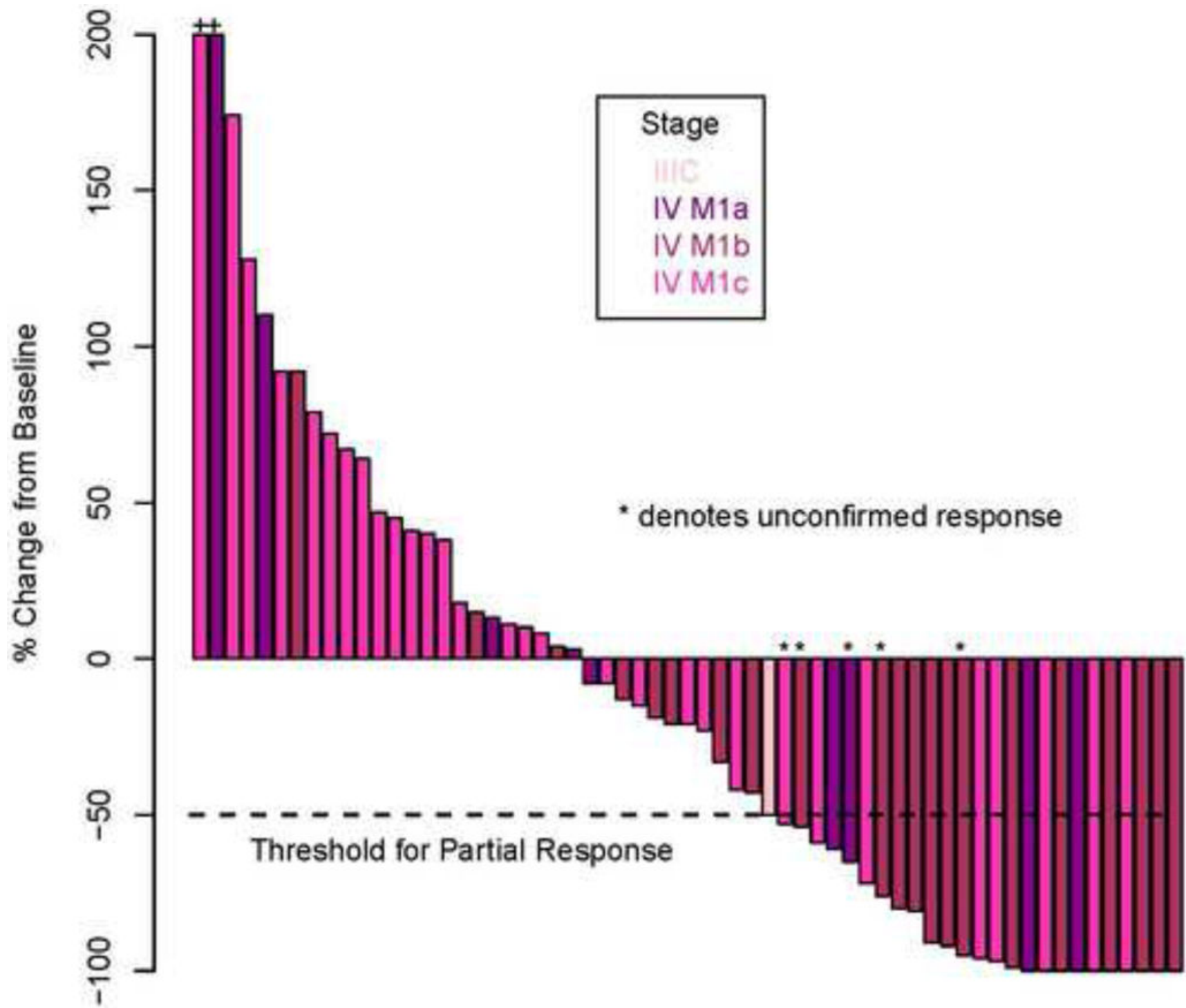

Figure 1.

Waterfall plot of best overall response using immune-related response criteria Confirmed Complete Response 15.6\% ( $\mathrm{n}=10)$; confirmed Partial Response 15.6\% ( $\mathrm{n}=10)$; Stable Disease $39.1 \%(n=25)$; Progression of Disease $25 \%(n=16) .3$ patients $(4.7 \%)$ did not have tumor assessment data and were, therefore, not evaluable. 

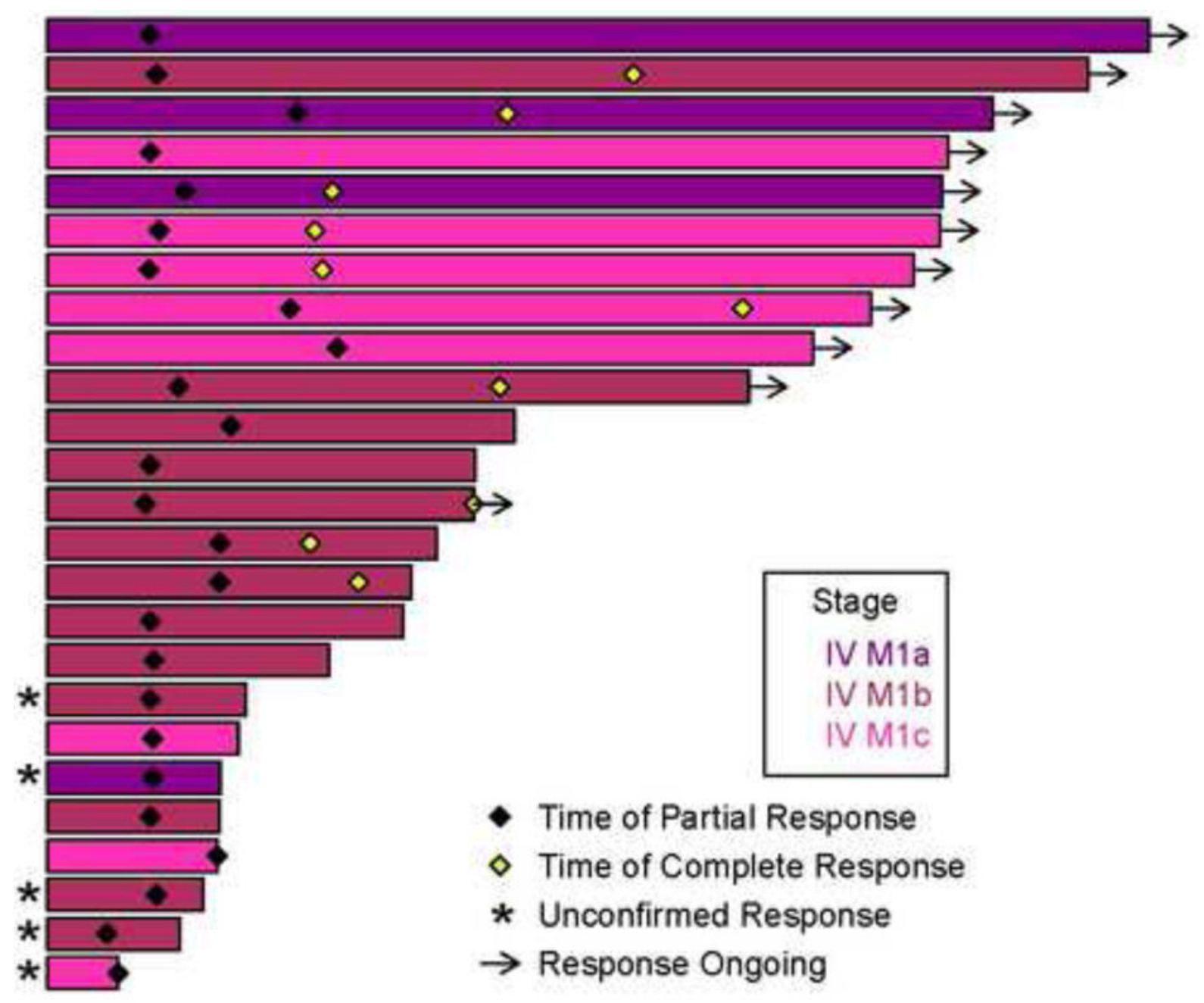

- Time of Partial Response

$\diamond$ Time of Complete Response

$\rightarrow$ Response Ongoing

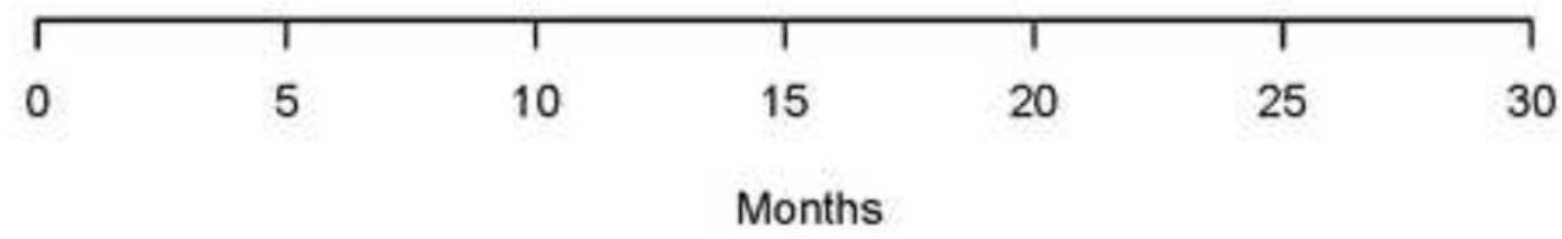

Figure 2.

Swimmer's plot denoting duration of response. The median duration of response was 35 months (range $2-57$ months). Partial responses were most often seen by 3 months, while complete responses were seen starting at 6 months to beyond 15 months. 
Patel et al.

A

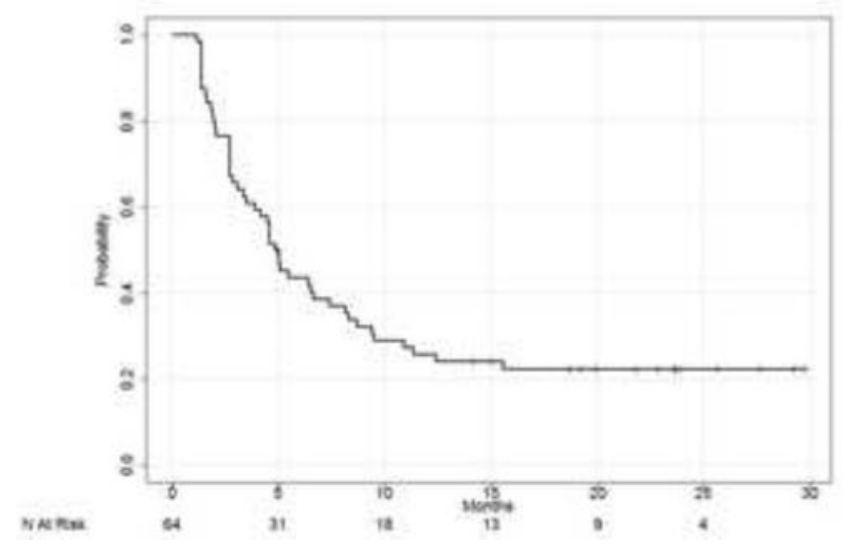

B

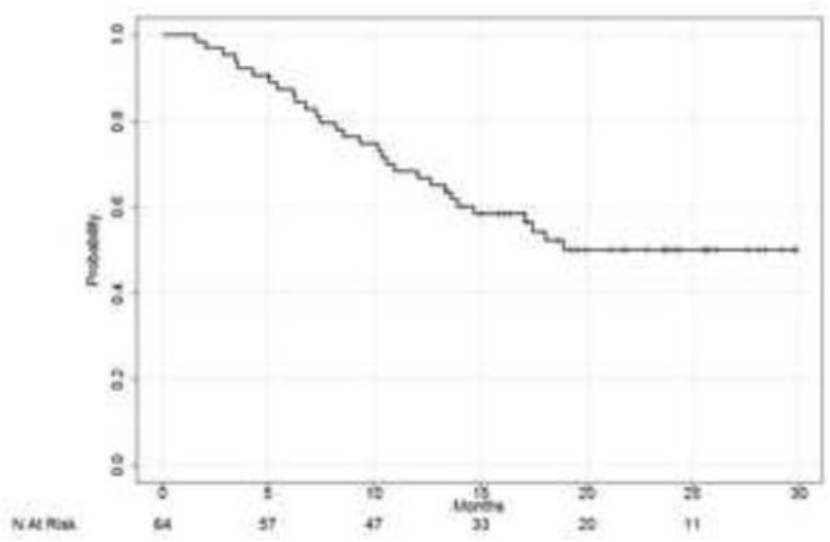

Figure 3.

Kaplan-Meier survival curves for total study population. Panel A: Progression-free survival (PFS); Median PFS 5.0 months. Panel B: Overall survival (OS); Median OS not reached. 


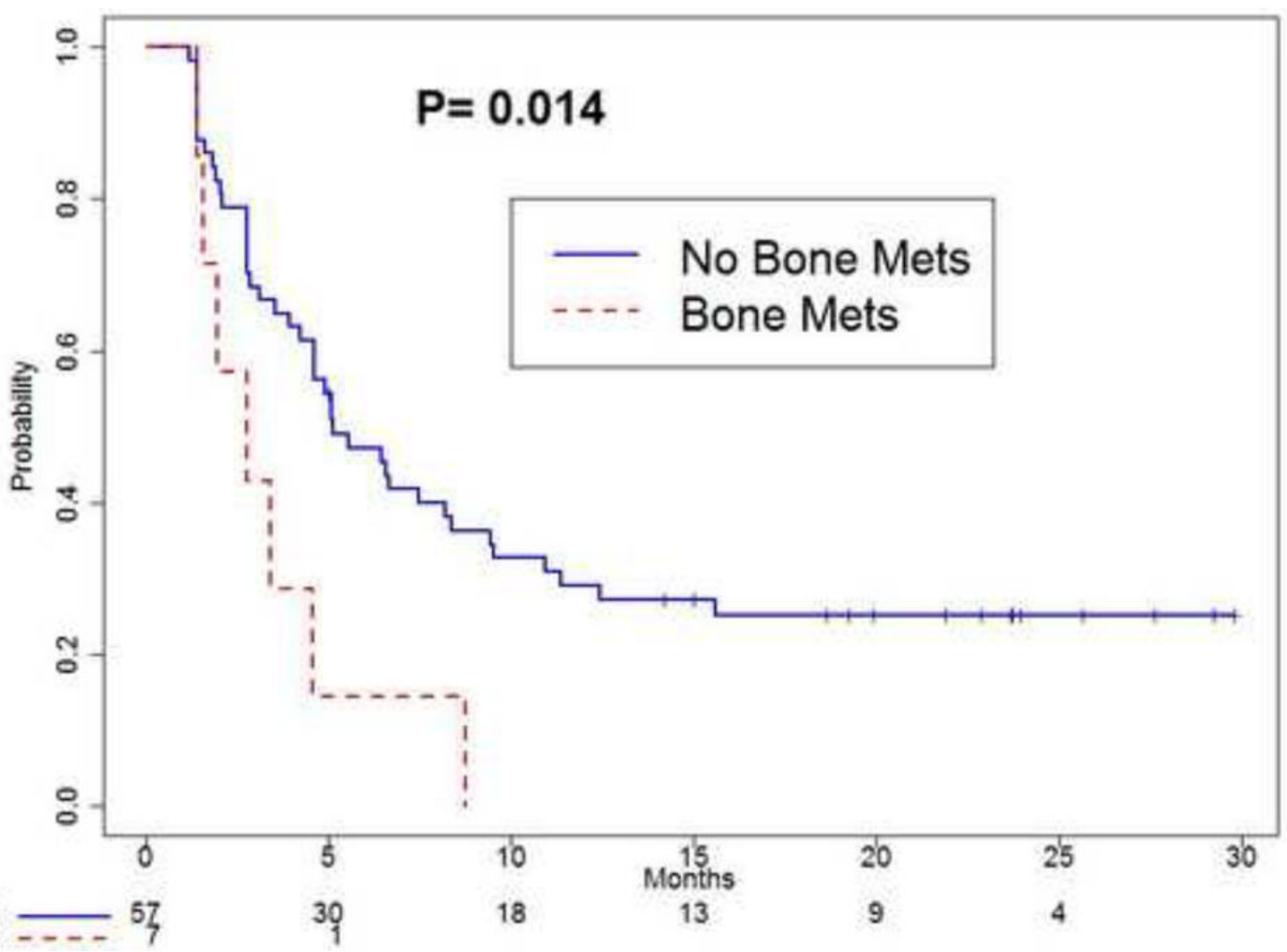

Figure 4.

PFS in patients with and without bone metastasis. Median PFS in patients with bone metastasis $(\mathrm{n}=7)$ was 2.8 months, 5.1 months in patients without bone metastasis $(\mathrm{n}=57)$. This difference was statistically significant $(p=0.014)$. Progression was defined per immune-related response criteria as increase in tumor burden (target and/or non-target lesions) of at least $25 \%$ compared with nadir. For this analysis, progression of disease was commonly driven by increase in size of bone metastasis (i.e., non-target lesions). 


\section{Table 1}

Baseline demographics

\begin{tabular}{|c|c|c|}
\hline & Characteristic & $N=64$ \\
\hline Median age (range) & & $62(33-75)$ \\
\hline \multicolumn{3}{|l|}{ Gender - no. $(\%)$} \\
\hline & Male & $45(70 \%)$ \\
\hline \multicolumn{3}{|l|}{ Race - no. $(\%)$} \\
\hline & Caucasian & $63(98 \%)$ \\
\hline & Hispanic & $1(2 \%)$ \\
\hline \multicolumn{3}{|c|}{ ECOG perfomance status - no. (\%) } \\
\hline & 0 & $53(83 \%)$ \\
\hline & 1 & $11(17 \%)$ \\
\hline \multicolumn{3}{|l|}{ Stage - no. $(\%)$} \\
\hline & IIIc & $2(3 \%)$ \\
\hline & M1a & $10(16 \%)$ \\
\hline & M1b & $21(33 \%)$ \\
\hline & M1c & $31(48 \%)$ \\
\hline \multicolumn{3}{|c|}{ BRAF V600 - no. (\%) } \\
\hline & Mutation & $22(34 \%)$ \\
\hline \multicolumn{3}{|c|}{ Brain metastasis - no. (\%) } \\
\hline & No & $62(97 \%)$ \\
\hline & Yes & $2(3 \%)$ \\
\hline \multicolumn{3}{|c|}{ Baseline LDH level - no. (\%) } \\
\hline & Normal & $51(80 \%)$ \\
\hline & Elevated & $13(20 \%)$ \\
\hline
\end{tabular}


Table 2

\section{Adverse Events}

\begin{tabular}{|c|c|c|c|}
\hline Common Toxicities & Total \# Patients (\%) & Grade $3(\%)$ & Grade $4(\%)$ \\
\hline Pruritus & $56(87.5)$ & $4(6)$ & 0 \\
\hline Skin rash & $53(83)$ & $6(9)$ & $1(1.6)$ \\
\hline Fatigue & $50(78)$ & $10(16)$ & 0 \\
\hline Nausea & $49(77)$ & $1(1.6)$ & 0 \\
\hline Constipation & $45(70)$ & $1(1.6)$ & 0 \\
\hline Diarrhea & $36(56)$ & $5(8)$ & $1(1.6)$ \\
\hline Vomiting & $33(52)$ & 0 & 0 \\
\hline Anorexia & $33(52)$ & $1(1.6)$ & 0 \\
\hline Dry skin & $33(52)$ & 0 & 0 \\
\hline Headache & $32(50)$ & 0 & 0 \\
\hline Pain & $23(40)$ & $5(8)$ & 0 \\
\hline Fever & $21(33)$ & 0 & 0 \\
\hline Dyspnea & $19(30)$ & $3(5)$ & 0 \\
\hline Colitis & $7(11)$ & $1(1.6)$ & 0 \\
\hline Laboratory toxicities & Total\# Patients (\%) & Grade $3(\%)$ & Grade $4(\%)$ \\
\hline \multicolumn{4}{|l|}{ HEMATOLOGIC } \\
\hline Anemia & $42(66)$ & 0 & 0 \\
\hline Neutropenia & $6(9)$ & $2(3)$ & $1(1.6)$ \\
\hline Lymphopenia & $15(23)$ & $1(1.6)$ & 0 \\
\hline Thrombocytopenia & $24(38)$ & $3(5)$ & $1(1.6)$ \\
\hline \multicolumn{4}{|l|}{ NON-HEMATOLOGIC } \\
\hline Hyperglycemia & $44(69)$ & $3(5)$ & 0 \\
\hline ALT (high) & $29(45)$ & $1(1.6)$ & 2(3) \\
\hline AST (high) & $27(42)$ & $2(3)$ & 1(1.6) \\
\hline Alk Phos (high) & $16(25)$ & $1(1.6)$ & 0 \\
\hline Total Bilirubin (high) & $10(16)$ & 0 & $1(1.6)$ \\
\hline Magnesium (low) & $17(27)$ & 1(1.6) & 0 \\
\hline Creatinine (high) & $16(25)$ & 0 & 0 \\
\hline Potassium (low) & $9(14)$ & 0 & 0 \\
\hline
\end{tabular}

Cancer Immunol Immunother. Author manuscript; available in PMC 2018 October 01. 